\title{
Human Missense Mutations in Regulator of G Protein Signaling 2 Affect the Protein Function Through Multiple Mechanisms ${ }^{\mathbf{S}}$
}

\author{
Hoa T. N. Phan, Benita Sjögren, and Richard R. Neubig \\ Department of Pharmacology and Toxicology, Michigan State University, East Lansing, Michigan \\ Received May 1, 2017; accepted August 2, 2017
}

\section{ABSTRACT}

Regulator of G protein signaling 2 (RGS2) plays a significant role in alleviating vascular contraction and promoting vascular relaxation due to its GTPase accelerating protein activity toward $\mathrm{G} \alpha \mathrm{q}$. Mice lacking RGS2 display a hypertensive phenotype, and several RGS2 missense mutations have been found predominantly in hypertensive human subjects. However, the mechanisms whereby these mutations could impact blood pressure is unknown. Here, we selected 16 rare, missense mutations in RGS2 identified in various human exome sequencing projects and evaluated their ability to inhibit intracellular calcium release mediated by angiotensin II receptor type 1 (AT1R). Four of them had reduced function and were further investigated to elucidate underlying mechanisms. Low protein expression, protein mislocalization, and reduced $G$ protein binding were identified as likely mechanisms of the malfunctioning mutants. The Q2L mutant had $50 \%$ lower RGS2 than wild-type (WT) protein detected by Western blot. Confocal microscopy demonstrated that $\mathrm{R} 44 \mathrm{H}$ and $\mathrm{D} 40 \mathrm{Y}$ had impaired plasma membrane targeting; only $46 \%$ and $35 \%$ of those proteins translocated to the plasma membrane when coexpressed with $\mathrm{G} \alpha_{\mathrm{q}}$ Q209L compared with 67\% for WT RGS2. The R188H mutant had a significant reduction in $\mathrm{G} \alpha_{\mathrm{q}}$ binding affinity (10-fold increase in $K_{\mathrm{i}}$ compared with WT RGS2 in a flow cytometry competition binding assay). This study provides functional data for 16 human RGS2 missense variants on their effects on AT1R-mediated calcium mobilization and provides molecular understanding of those variants with functional loss in vitro. These molecular behaviors can provide insight to inform antihypertensive therapeutics in individuals with variants having reduced function.

\section{Introduction}

Heart and cerebrovascular diseases have remained the major causes of death and disability in the United States (Heron, 2016; Mozaffarian et al., 2016) despite relentless efforts in cardiovascular research and drug development. Hypertension is a multifactorial disorder that places individuals at a higher risk for such diseases. Multiple genomewide association studies have discovered polymorphisms in genes and loci that are associated with hypertension (Adeyemo et al., 2009; Levy et al., 2009; Newton-Cheh et al., 2009; Dominiczak and Munroe, 2010; Lind and Chiu, 2013; Franceschini et al., 2014; Huan et al., 2015; Pan et al., 2015). However, current knowledge about hypertension genetics is still far from complete. Common variants identified in genomewide association studies only explain a small fraction of the blood pressure variance landscape (Dominiczak and Munroe, 2010). This limitation highlights the need to study rare variants that may contribute to this complex disorder (Schork et al., 2009; Gibson, 2012).

This work was supported by the American Heart Association predoctoral fellowship [15PRE24680004] to H.T.N.P). The MSU College of Veterinary Medicine George Ward Endowed Research Fund and the MSU AgBioResearch provided financial support for the Hamamatsu plate reader.

https://doi.org/10.1124/mol.117.109215.

S This article has supplemental material available at molpharm.aspetjournals. org.
G protein coupled receptors (GPCRs) play a critical role in vascular tone regulation (Brinks and Eckhart, 2010). Several GPCRs with preferential activation of heterotrimeric $G$ proteins of the $\mathrm{G} \alpha_{\mathrm{q}}$ family (e.g., angiotensin II, endothelin, and $\alpha 1$ adrenergic receptors) mediate vasoconstrictor responses in blood vessels and many antihypertensive drugs act to counteract their effects. Regulator of G protein signaling (RGS) proteins plays a crucial role in modulating GPCR signaling through its GTPase-activating protein activity toward $\mathrm{G} \alpha$ subunits. Regulator of $\mathrm{G}$ protein signaling 2 , in particular, has been strongly implicated in cardiovascular regulation due to its selectivity toward $\mathrm{G} \alpha_{\mathrm{q}}$, resulting in diminished vasoconstrictor action (Heximer et al., 1997). Homozygous and heterozygous RGS2 knockout mice exhibit a hypertension phenotype attributed to prolonged $\mathrm{G} \alpha \mathrm{q}$-mediated vasoconstrictor signaling (Heximer et al., 2003) and a reduced nitric oxide/cGMP-mediated vascular relaxation response (Tang et al., 2003; Sun et al., 2005). Mice lacking RGS2 are also prone to cardiac hypertrophy due to elevated $\mathrm{G} \alpha \mathrm{q}$ signaling (Zhang et al., 2006). Increased sympathetic tone and altered renal mechanisms also contribute substantially to hypertension development in RGS2 knockout mice (Gross et al., 2005; Gurley et al., 2010; Osei-Owusu et al., 2015).

The actual role of RGS2 in human hypertension is not well understood. A number of common variants in the promoter, introns, and noncoding regions of RGS2 gene are associated with hypertension and suboptimal responsiveness to antihypertensive

ABBREVIATIONS: AT1R, angiotensin II type 1 receptor; CHO, Chinese hamster ovary cells; GPCR, G protein-coupled receptor; HEK-293, human embryonic kidney 293 cells; MBP, maltose binding protein; PBS, phosphate-buffered saline; PCR, polymerase chain reaction; PM, plasma membrane; RGS, regulator of G protein signaling; UTR, untranslated region; WT, wild type. 
treatment in different ethnic groups (Yang et al., 2005; Riddle et al., 2006; Semplicini et al., 2006; Freson et al., 2007; Zhang et al., 2013). Several reported missense mutations in RGS2 were found predominantly in hypertensive subjects but with very low allele frequencies (Yang et al., 2005). Among those, the Q2L mutant allele was shown to have low protein expression due to rapid proteasomal degradation (Bodenstein et al., 2007; Park et al., 2015). The R44H mutant, on the other hand, showed less efficient plasma membrane targeting ( $\mathrm{Gu}$ et al., 2008). Because these missense mutations of RGS2 had such low allele frequencies $(<1 \%)$, it has been difficult to determine the functional significance of these mutations using epidemiologic or informatics approaches.

The revolution in next-generation sequencing has revealed genetic information useful for prevention and clinical management (Rabbani et al., 2014). More commonly, healthcare professionals are presented with variants of uncertain significance, which complicates the interpretation of genetic data (Ackerman, 2015; Gómez et al., 2016). Computational tools have been developed to predict variant effects with limited success (Schulz et al., 2015). Definitive characterization of variants of uncertain significance requires family segregation or functional studies. In alignment with this common theme, many missense mutations of RGS2 have been released to public databases such as NHLBI GO Exome Sequencing project (http://evs.gs.washington.edu/EVS/) and Exome Aggregation Consortium (ExAC at http://exac.broadinstitute. org), but the functional consequences and human phenotypes of these variants is largely unknown.

We hypothesized that changes in the coding sequence of RGS2 may result in protein products that have altered function. In this study, we examined 16 mutations (Table 1) found in a Japanese population (Yang et al., 2005), the NHLBI exome sequencing project (Fu et al., 2013), and the ExAC database (Lek et al., 2016) to determine whether they differ from wild-type (WT) RGS2 in their ability to regulate GPCRmediated signaling. For those with reduced function, we determined the molecular characteristics contributing to those differences. Specifically, we investigated the protein levels, protein localization, and $\mathrm{G}$ protein binding activities of these mutants to further our understanding about the underlying mechanisms responsible for functional alteration of the mutants. Only a small fraction of variants showed altered function, and it was due to several distinct mechanisms.

\section{Materials and Methods}

DNA Constructs. Mammalian expression vectors encoding the human, full-length, untagged or 3xHA tagged WT angiotensin II type 1 receptor (AT1R) and RGS2 in pcDNA3.1(+) were obtained from the University of Missouri-Rolla cDNA Resource Center (http://www. cdna.org). Other constructs were generated in our laboratory and the primer sequences for construct generation are available on request. RGS2 was amplified by polymerase chain reaction (PCR) as attB1-2 fragments without a stop codon to allow subsequent cloning to an entry vector pDONR221 using Gateway BP clonase (Invitrogen, Carlsbad, CA). RGS2-Q2L, RGS2-Q2R, RGS2-S3G, RGS2-A4V, RGS2M5V, RGS2-K18N, RGS2-G23D, RGS2-D40Y, RGS2-R44H, RGS2-Q50K, RGS2-P55L, RGS2-Q78H, RGS2-A99G, RGS2-I110V, RGS2-R188H, and RGS2-Q196R were generated in the entry vector by performing QuikChange site-directed mutagenesis (Stratagene, La Jolla, CA). RGS2 WT and mutants were transferred into C-terminally V5 or GFP epitope-tagged expression vector (pcDNA3.2DEST or pcDNADEST47, respectively) using Gateway LR clonase (Invitrogen). A pMAL$\mathrm{C} 2 \mathrm{H} 10 \mathrm{~T}$ construct encoding the $\mathrm{RH}$ domain of human RGS2 (residues 72-203) was a kind gift from Dr. John J. Tesmer (University of Michigan). Mutagenesis for this vector was performed as described above. The open reading frame of all PCR and mutagenesis generated constructs was verified by sequencing at the RTSF Genomics Core at Michigan State University.

Cell Culture and Transfections. All cell lines were maintained in a humidified incubator at $37^{\circ} \mathrm{C}$ with $5 \% \mathrm{CO}_{2}$. Human embryonic kidney 293 (HEK-293) cells were grown to 95\% confluence in Dulbecco's modified Eagle's medium (GIBCO, Carlsbad, CA), supplemented with $10 \%$ fetal bovine serum, $100 \mathrm{U} / \mathrm{ml}$ penicillin, and $100 \mathrm{mg} / \mathrm{ml}$ streptomycin. Chinese hamster ovary (CHO-K1) cells (American Type Culture Collection, Manassas, VA) were grown to 95\% confluence in Ham's F-12 nutrient mixture (GIBCO), supplemented with $10 \%$ fetal bovine serum, $100 \mathrm{U} / \mathrm{ml}$ penicillin, and $100 \mathrm{mg} / \mathrm{ml}$ streptomycin. HEK293 and CHO-K1 cells were transiently transfected using, respectively, X-tremeGENE HP DNA Transfection Reagent (Roche Life Sciences, Indianapolis, IN) at $2 \mathrm{ml} / \mathrm{mg}$ of plasmid DNA and DNA-In CHO (MTI-GlobalStem, Gaithersburg, MD) at $3 \mathrm{ml} / \mathrm{mg}$ of plasmid DNA according to the manufacturers' recommended protocols. Transfection mixes were prepared in Opti-MEM (GIBCO) and all transfections

TABLE 1

Missense mutations in the coding region of RGS2 used in this study

ExAC denotes the Exome Aggregation Consortium (http://exac.broadinstitute.org).

\begin{tabular}{llcll}
\hline \multicolumn{1}{c}{ Mutation ID } & $\begin{array}{c}\text { Missense } \\
\text { Variant }\end{array}$ & $\begin{array}{c}\text { Allele Count } \\
\text { (ExAC) }\end{array}$ & Codon Change & \multicolumn{1}{c}{ Reference } \\
\hline NA & Q2L $^{a}$ & $2 / 121304$ & CAA > CTA & Yang et al. (2005); Lek et al. (2016) \\
rs141030117 & Q2R & $65 / 121312$ & CAA > CGA & Yang et al. (2005); Lek et al. (2016) \\
rs145125159 & S3G & $32 / 121316$ & AGT > AGC & Yang et al. (2005); Lek et al. (2016) \\
rs142499684 & A4V & $4 / 121338$ & GCT > GTT & Lek et al. (2016) (20) \\
rs193051407 & M5V & $82 / 121346$ & ATG > GTG & Yang et al. (2005); Lek et al. (2016) \\
rs74466425 & K18N & $34 / 121370$ & AAG > AAC & Lek et al. (2016) \\
rs148489044 & G23D & $66 / 121358$ & GGC > GAC & Lek et al. (2016) \\
rs201233692 & D40Y & $62 / 118360$ & GAT > TAT & Lek et al. (2016) \\
rs200339834 & R44H & $12 / 119308$ & CGT > CAT & Yang et al. (2005); Lek et al. (2016) \\
rs80221024 & Q50K & $103 / 119910$ & CAA > AAA & Lek et al. (2016) \\
rs140811638 & P55L & $6 / 120456$ & CCT > CTT & Lek et al. (2016) \\
NA & Q78H & $3 / 2055$ & CAG > CAC & Yang et al. (2005) \\
rs139237239 & A99G & $2 / 121332$ & GCT > GGT & Lek et al. (2016) \\
rs146862218 & I110V & $53 / 121334$ & ATT > GTT & Lek et al. (2016) \\
rs369752935 & R188H & $4 / 121388$ & CGT > CAT & Lek et al. (2016) \\
rs112707798 & Q196R & $18 / 121352$ & CAG > CGG & Lek et al. (2016) \\
\hline
\end{tabular}

NA, not applicable.

${ }^{a}$ RGS2 mutations were found in disease cohort (Yang et al., 2005). 
were performed under antibiotic-free conditions. Experiments were run 24 to 48 hours after transfection.

SDS-PAGE and Western Blot Analysis. Twenty-four hours after transfection, the cells were treated as indicated in the figure legend and harvested using modified RIPA lysis buffer containing $50 \mathrm{mM}$ Tris $\mathrm{HCl} \mathrm{pH} \mathrm{7.4,1 \%} \mathrm{NP-40,} \mathrm{0.5 \%} \mathrm{sodium} \mathrm{deoxycholate,} 0.1 \%$ SDS, $150 \mathrm{mM} \mathrm{NaCl}, 2 \mathrm{mM}$ EDTA, supplemented with complete protease inhibitor (Roche Diagnostics, Indianapolis, IN). Protein concentration in the cell lysates was determined using the BCA assay (Pierce, Rockford, IL) and adjusted with an appropriate volume of Laemmli buffer (BioRad Laboratories, Hercules, CA). Equal amounts of protein in each lane were resolved on a 12\% SDS-PAGE gel for 1 hour at $180 \mathrm{~V}$. Samples were transferred to an Immobilon-FL membrane (EMD Millipore, Darmstadt, Germany) for 1 hour at $100 \mathrm{~V}$, $400 \mathrm{~mA}$ on ice and subjected to Western immunoblot analysis. The membrane was blocked with Odyssey blocking buffer (phosphatebuffered saline [PBS]) (Li-Cor Biosciences, Lincoln, NE) for 30 minutes at room temperature on an orbital shaker. The membrane was probed overnight at $4^{\circ} \mathrm{C}$ with primary antibody diluted in blocking buffer. Mouse anti-V5 antibody (cat. no. 46-0705, lot no. 1620500; Invitrogen), rabbit anti-HA (cat. no. sc-805, lot no. D0413; Santa Cruz Biotechnology, Dallas, TX) and rabbit anti-actin (cat. no. sc-1615-R, lot no. C2609; Santa Cruz Biotechnology) were used at a dilution of 1:5000, 1:1000 and 1:1000, respectively. The membrane was washed with PBS buffer supplemented with $0.1 \%$ Tween 20 (PBS-T) 4 times and probed for 1 hour at room temperature with IRDye-conjugated secondary antibody diluted in blocking buffer. IRDye 680RD donkey antimouse (cat. no. 926-68072, lot no. C31216-02) and IRDye 800CW donkey anti-rabbit antibody (cat. no. 926-32213, lot no. C40130-03) (1: 10,000) were from Li-Cor Biosciences. After four washes in blocking buffer, the protein bands were visualized using Li-Cor Odyssey FC scanner and images were scanned and analyzed using the Image Studio Lite (Li-Cor Biosciences).

Confocal Microscopy. HEK293 cells were seeded into collagencoated $35 \mathrm{~mm}$ glass-bottom Petri dishes (MatTek Corporation, Ashland, MA) and transfected with $0.5 \mu \mathrm{g}$ of plasmid DNA encoding RGS2-GFP with or without $0.5 \mu \mathrm{g}$ of plasmid encoding $\mathrm{G} \alpha_{\mathrm{q}}^{\mathrm{Q} 209 \mathrm{~L}}$. Confocal microscopy was performed on live cells 24 hours after transfection using an Olympus FluoView 1000 laser scanning confocal microscope. Images represent single planes on the basal side of the cell obtained with an original magnification $60 \times$ oil objective using $488 \mathrm{~nm}$ excitation and 505-530 $\mathrm{nm}$ emission wavelengths for GFP. Shown are pictures representative of at least 100 live cells from three independent experiments. Densitometric quantitation of protein expression was performed in a blinded manner using the line scan analysis function of the ImageJ software package.

$\mathbf{C a}^{2+}$ Mobilization Assays. Twenty-four hours after transfection, CHO cells were split into black, flat, clear bottom 384-well plates (Greiner Bio-one, Kremsmünster, Austria) and allowed to attach overnight. The medium was aspirated and cells loaded with $1 \mathrm{X}$ fluo4 NW (Molecular Probes, Eugene, OR) in a loading buffer consisting of Hank's basal saline solution supplemented with $20 \mathrm{mM}$ HEPES, $\mathrm{pH}$ 7.4 and $2.5 \mu \mathrm{M}$ probenecid following manufacturer's protocol. The cells were incubated for 30 minute at $37^{\circ} \mathrm{C}$, then 30 minute at room temperature. Dye mix was removed and loading buffer was added to the cell plate. A concentration gradient of angiotensin II (cat. no. A9525; Sigma-Aldrich, St. Louis, MO) at 2 times the final concentration was freshly prepared in loading buffer supplemented with $0.1 \%$ bovine serum albumin for automated injection into the wells by a FDSS $/ \mu$ Cell kinetic fluorescence plate reader (Hamamatsu Photonics KK, Hamamatsu City, Japan). Assay plates were then placed onto the plate reader for measuring the changes of intracellular free calcium in response to the receptor activation.

Protein Expression and Purification. The RGS domain of WT and mutant RGS2 was expresses as a C-terminal fusion on bacterial maltose binding protein (MBP). Protein was purified as described previously (Shankaranarayanan et al., 2008). All proteins had similar purity and concentration (Supplemental Fig. 1). Biotinylated $\Delta \mathrm{N}-\mathrm{G} \alpha \mathrm{q}$ encoding residues 35-359 of murine $\mathrm{G} \alpha_{\mathrm{q}}$ was a gift from Dr. John J. Tesmer (University of Michigan).

Flow Cytometry Protein-Interaction Assays. The binding between $\mathrm{G} \alpha_{\mathrm{q}}$ with MBP-RGS2 and its point mutants were determined by a flow cytometry based assay (Roman et al., 2007; Nance et al., 2013). MBP-RGS2 $2^{72-203}$ was fluorescently labeled with amine reactive Alexa Fluor 532 NHS ester (Molecular Probes). Biotinylated murine $\mathrm{G} \alpha_{\mathrm{q}}$ was attached to xMAP LumAvidin beads (Luminex, Austin, TX). The indicated concentration of unlabeled MBP-RGS2 WT and mutants were used to compete with $80 \mathrm{nM}$ of the Alexa Fluor 532 labeled WT MBP-RGS2. Binding was performed as described (Nance et al., 2013) in a full skirt 96-well plate (BioExpress, Kaysville, UT). Samples were analyzed on a Luminex 200 flow cytometer, collecting at least 100 events per well. Data from at least four independent experiments of duplicate samples were fit by nonlinear regression using GraphPad Prism 7 (GraphPad Software, LaJolla, CA). $K_{\mathrm{i}}$ values were calculated using the Cheng-Prusoff equation.

Differential Scanning Fluorometry Analysis. MBP-RGS2 proteins were cleaved using TEV protease (Promega, Madison, WI) and the RGS2 WT and mutant RGS domains were purified using Ni resin (Supplemental Fig. 1). Differential scanning fluorometry analysis was performed in triplicate in 96-well plates in final volume of $20 \mu \mathrm{l} /$ well. Protein $(7 \mu \mathrm{M}$ final) was prepared in $20 \mathrm{mM}$ HEPES, $\mathrm{pH}$ 8.0, $500 \mathrm{mM} \mathrm{NaCl}, 2 \mathrm{mM}$ dithiothreitol, and $1 \times$ protein thermoshift dye (cat. no. 4461146; Applied Biosystems, Foster City, CA) according to the manufacturer's protocol. The samples were heated from 25 to $99^{\circ} \mathrm{C}$ with a ramp rate of $1^{\circ} \mathrm{C}$ in continuous mode in an ABI 7500-Fast Real time PCR (Applied Biosystems). Data for the melting curves were analyzed in GraphPad Prism 7 (GraphPad Software) using the Boltzmann sigmoidal equation to obtain the melting temperature.

Structure Modeling. The structure of human RGS2 in complex with murine $\mathrm{G} \alpha_{\mathrm{q}}$ R183C (Protein Data Bank, 4EKD) was modified to mimic the $\mathrm{R} 188 \mathrm{H}$ mutant using the Pymol mutagenesis tool. The rotamer of the modified amino acid with least steric interference was chosen on the basis of least overlap of van der Waals radii.

Data Analysis and Statistics. All data were analyzed using GraphPad Prism 7.0 (GraphPad Software). The dose-response curves were fit using nonlinear regression [log(agonist) vs. response - Variable slope (four parameters)]. Data sets with three or more groups were analyzed with one-way analysis of variance with Bonferroni's post hoc test for multiple comparisons (unless indicated otherwise in the figure legend). Data are presented as mean \pm S.E.M., and a $P$ value $<0.05$ was considered significant.

\section{Results}

Differential Effects of Human RGS2 Mutants to Inhibit AT1R-Mediated Intracellular Calcium Release. In the current study, we investigated the biochemical properties of 16 single-nucleotide polymorphisms in the coding region of RGS2 previously identified in humans (Fig. 1A). As an initial screen to determine the function of RGS2 mutants, CHO cells were cotransfected with cDNAs encoding AT1R $(1 \mu \mathrm{g})$ and WT or mutant RGS2 $(0.75 \mu \mathrm{g})$. At this ratio, the suppression of AT1R-stimulated $\mathrm{Ca}^{2+}$ release by RGS2 was submaximal, enabling the identification of both gain- and lossof-function mutations (Supplemental Fig. 2). In the absence of RGS2, AT1R stimulation by angiotensin II caused a rapid and transient peak of intracellular calcium $\left[\mathrm{Ca}^{2+}\right]_{\mathrm{i}}$ (Fig. 1, B and C). Maximal $\left[\mathrm{Ca}^{2+}\right]_{\mathrm{i}}$ obtained from the dose-response curves in cells expressing receptor without RGS2 (Fig. 1, D and E) was set as $100 \%$. WT RGS2 protein coexpression inhibits peak $\left[\mathrm{Ca}^{2+}\right]_{\mathrm{i}}$ by $48 \% \pm 2 \%$ (Fig. 1, B, C, and F) and increases the $\mathrm{EC}_{50}$ from $4.2 \pm$ $0.3 \mathrm{nM}$ to $7.9 \pm 0.7 \mathrm{nM}$ (Supplemental Table 1) without changing the receptor protein level (Supplemental Fig. 3). Four mutants, 


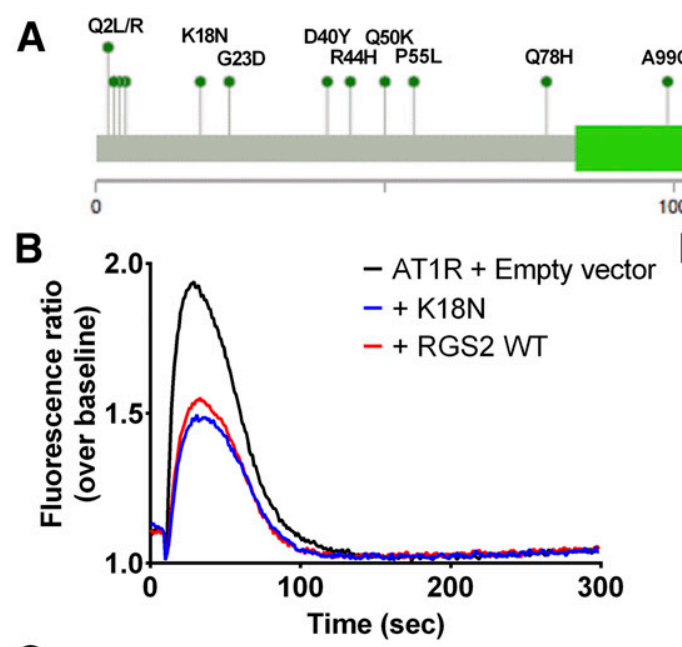

C

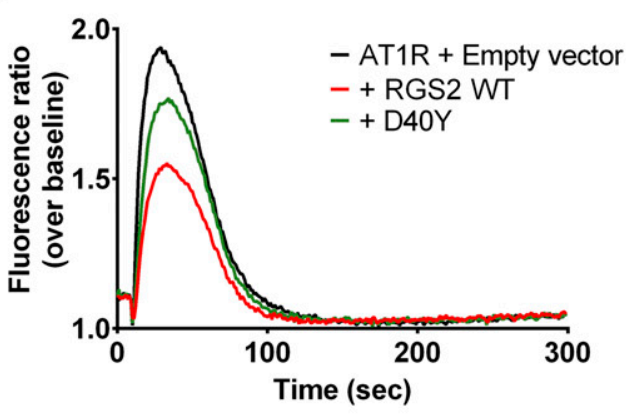

E
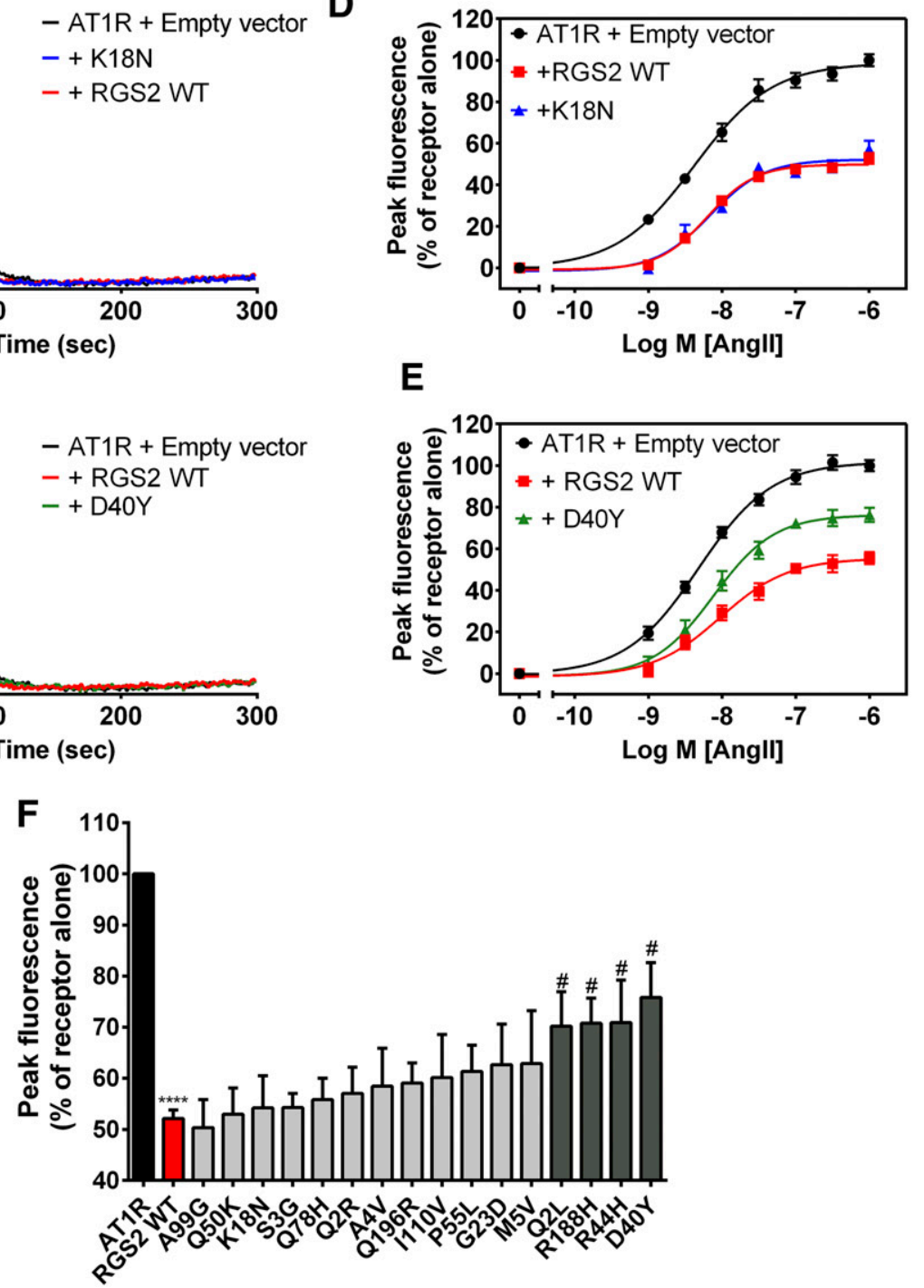

Fig. 1. Impact of RGS2 mutations on AT1R-mediated intracellular calcium release. (A) RGS2 mutation map. Needle plot showing the two-dimensional positions of 16 missense mutations on the human RGS2 protein. The plot was visualized by inputting amino acid changes of RGS2 protein to MutationMapper tool (cBioPortal). CHO cells transiently expressing AT1R receptor with or without RGS2 WT or RGS2 mutants were used for measurement of intracellular $\mathrm{Ca}^{2+}$. (B and C) Representative fluorescence traces (angiotensin II, $1 \mu \mathrm{M}$ ) from cells expressing AT1R alone (black), cells coexpressing AT1R and RGS2 WT, K18N (normal function), or D40Y (decreased function). (D and E) Concentration-response curves. K18N inhibits AT1R-mediated $\mathrm{Ca}^{2+}$ as equally as RGS2 WT while D40Y showed reduced inhibition as compared with WT. (F) Bar graph of maximal percentage inhibition mediated by RGS2 WT or mutants. Reduced function mutants are shown in dark gray (Q2L, R188H, R44H, D40Y) and mutants that did not show a significant difference from WT (uncorrected $P>0.05$ ) are shown in light gray. $* * * * P<0.0001$ compared with AT1R + control, ${ }^{\#} P<0.05$ compared with AT1R + RGS2 WT ( $n=6-8$, Student $t$ test).

including the Q2L, R188H, R44H, and D40Y, showed reduced function (Fig. 1, C, E, and F). The 12 remaining mutants had comparable inhibitory effects to RGS2-WT. Therefore, they are considered to have normal function in this screen (Fig. 1, B, D, and $\mathrm{F}$ ). There was no significant change in $\mathrm{EC}_{50}$ mediated by RGS2 mutants compared with RGS2 WT (Supplemental Table 1).

Transient Protein Expression Levels of C-Terminal V5 Tagged RGS2. Differential protein expression could explain the different effects of these mutations. Specifically, the Q2L mutant has been shown to have low protein levels in HEK-293T (Bodenstein et al., 2007) and HeLa cells (Park et al., 2015) due to enhanced proteasomal degradation. In this study, we expressed C-terminal V5 tagged RGS2 WT and mutant constructs in CHO cells, and the total cell lysates were probed with V5 tag antibody using Western blot analysis. Consistent with previous work, the Q2L protein levels were also low in $\mathrm{CHO}$ cells (60\% reduction, $P<0.05$; Fig. 2 ) due to 

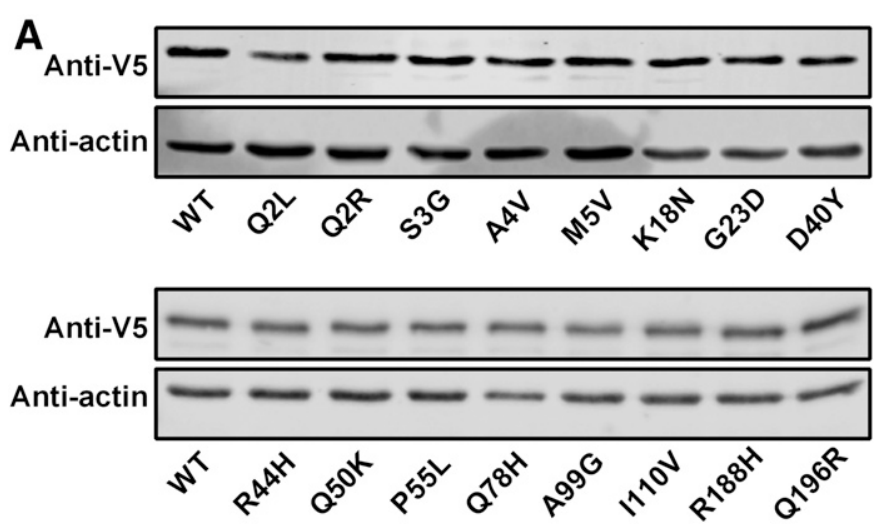

B

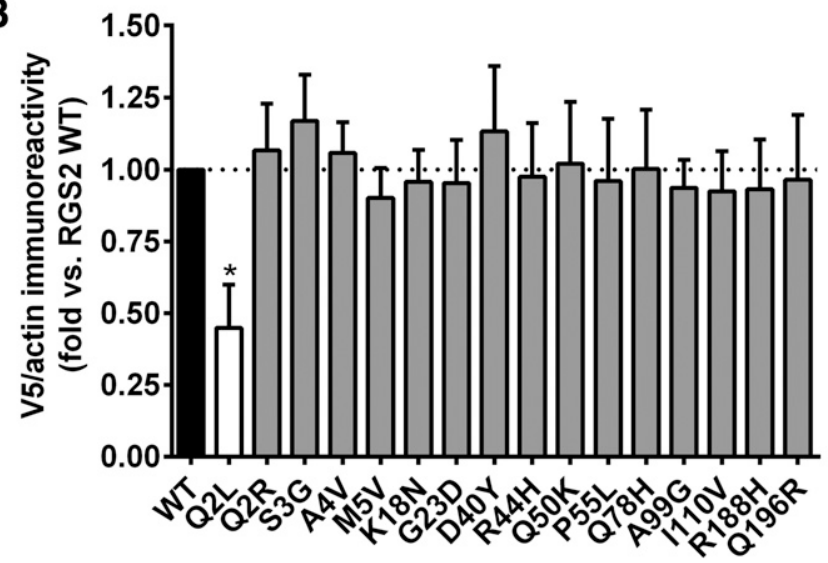

Fig. 2. Protein expression of RGS2 WT and mutants. CHO cells were transiently transfected with the V5-tagged (RGS2-V5) constructs; RGS2 protein levels were analyzed by anti-V5 Western blot. (A) Representative Western blot of 10 independent experiments showing results with total cell lysates of CHO cells expressing RGS2 WT and RGS2 mutant proteins. (B) Quantification of band intensities is normalized to the RGS2 WT protein level. Data are presented as mean \pm S.E.M. $* P<0.05$ (one-way analysis of variance with Bonferroni post-test).

rapid protein turnover $\left(t_{1 / 2}\right.$ Q2L: $6 \pm 1$ minute versus RGS2 WT: $17 \pm 4$ minutes) (Supplemental Fig. 4). None of the other 15 mutants showed low protein expression as compared with RGS2 WT (Fig. 2).

D40Y and R44H Mutants are Mislocalized. Two of the mutants with reduced function, D40Y and R44H, had disrupted plasma membrane (PM) localization (Fig. 3) This had previously been demonstrated for the R44H mutant ( $\mathrm{Gu}$ et al., 2008). In HEK-293 cells transfected with C-terminal GFPtagged RGS2, nearly $100 \%$ localized in the nucleus when it was expressed alone (Fig. 3, A-C and I). Cotransfection with $\mathrm{G} \alpha_{\mathrm{q}} \mathrm{Q} 209 \mathrm{~L}$ induced $67 \%$ of WT RGS2 to translocate to the PM (Fig. 3, E, J, and K). The Q2L mutant had a similar translocation level compared with RGS2 WT (Fig. 3K). The R44H mutant, as expected, had less protein localizing to the PM ( $21 \% \pm 2 \%$ less than WT RGS2, $P<0.0001$; Fig. 3, G, J, and K). The D40Y mutant was also less efficiently translocated with only $35 \%$ protein in the PM $(32 \% \pm 2 \%$ less than RGS2 WT, $P<0.0001$; Fig. 3, F, J, and K). A fraction of total R188H-GFP protein formed multiple aggregates throughout the cytoplasm either with or without $\mathrm{G} \alpha_{\mathrm{q}} \mathrm{Q} 209 \mathrm{~L}$ coexpression (white arrow, Fig. 3, D and H).

Biochemical Characteristics of RGS2 Mutants: RGS2$\mathbf{G} \boldsymbol{\alpha}_{\mathbf{q}}$ Binding and Thermal Stability. Among the 16 RGS2 mutants investigated, there are four mutations located in the
RGS domain of RGS2: A99G, I110V, R188H, and Q196R. Only the $\mathrm{R} 188 \mathrm{H}$ mutant was identified as having reduced function. We hypothesized that that mutation could interfere with the binding of RGS2 and $\mathrm{G} \alpha_{\mathrm{q}}$, thereby reducing the GTPase accelerating protein activity of RGS2 toward $\mathrm{G} \alpha_{\mathrm{q}}$. The binding of fluorescently labeled MBP-RGS2 WT to biotinylated $\mathrm{G} \alpha_{\mathrm{q}}$ was measured by flow cytometry protein-interaction assay. The $K_{\mathrm{d}}$ in saturation binding studies was $83 \pm 5 \mathrm{nM}$. We performed competition binding measurements in which various concentrations of unlabeled MBP-RGS2 WT or mutants were mixed with $80 \mathrm{nM}$ fluorescently labeled MBP-RGS2 WT then incubated with $\mathrm{AlF}_{4}^{-}$activated $\mathrm{G} \alpha_{\mathrm{q}}$ bound to microspheres. Bound, labeled RGS2 was analyzed by flow cytometry. All MBP-RGS2 variants were further purified by gel filtration to ensure similar purity and then concentrated to approximately a $90 \mu \mathrm{M}$ stock. The $K_{\mathrm{i}}$ values of each mutant were calculated from $\mathrm{IC}_{50}$ values derived from the curves, using the Cheng-Prussoff equation in GraphPad Prism. Most RGS2 proteins-WT, Q196R, Q78H, and A99Ghad similar $K_{\mathrm{i}}$ values: $19,20,18$, and $15 \mathrm{nM}$, respectively. The $\mathrm{R} 188 \mathrm{H}$ mutant, on the other hand, had a much lower affinity ( $K_{\mathrm{i}} 233$ nM; Fig. 4A).

We also measured the thermal stability of the $\mathrm{R} 188 \mathrm{H}$ and Q196R mutants using differential scanning fluorometry. The melting temperatures of WT RGS2 and Q196R were similar: $46.8^{\circ}$ and $49^{\circ} \mathrm{C}$, respectively. $\mathrm{R} 188 \mathrm{H}$ had a significantly lower melting temperature at $40^{\circ} \mathrm{C}$, which reflects markedly lower protein stability ( $P<0.001$; Fig. 4B). R188H also had significantly higher basal fluorescence, indicating a less stable protein (Supplemental Fig. 5). This measure of protein stability, however, did not correlate with protein stability in cells. The proteasome inhibitor MG-132 increased protein levels of R188H with a similar magnitude as that of RGS2 WT (Supplemental Fig. 6).

\section{Discussion}

Over 70 rare nonsynonymous RGS2 mutations have been identified in humans through multiple exome sequencing projects, and these may contribute to a propensity for hypertension. Of these, 32 mutations have been reported in at least two individuals, with the Q50K mutant having the highest allele frequency of $0.08 \%$ of overall population. Data are publicly available through the Exome Aggregation Consortium. In this study, we focused on 16 mutations (nonsynonymous polymorphisms) that were found in at least two individuals in both the ExAC and the NHLBI GO Exome Sequencing project databases. We identified four mutations that result in RGS2 proteins that display a functional deficit in inhibiting AT1Rmediated increases in intracellular calcium in $\mathrm{CHO}$ cells. Of these four, the results with the D40Y and R188H mutants are novel, and the Q2L and R44H mutants have been investigated in the past. Lower basal protein expression, impaired plasma membrane targeting, and $\mathrm{G}$ protein binding deficiency were identified as the mechanisms most likely responsible for the reduced function of these mutants.

Multiple $\mathrm{G} \alpha_{\mathrm{q}}$ coupled receptors have been used to probe RGS2 function in vitro such as M1 or M3 muscarinic receptors (Bodenstein et al., 2007; Gu et al., 2007, 2008) or the vasopressin receptor (Osei-Owusu et al., 2007). In this study, we chose the angiotensin II receptor because of its relevance in systematic regulation of vascular function and blood pressure (de Kloet et al., 2015; Cameron et al., 2016; Li and Zhuo, 2016). Moreover, RGS2 has been proposed to serve as a selective and potent 

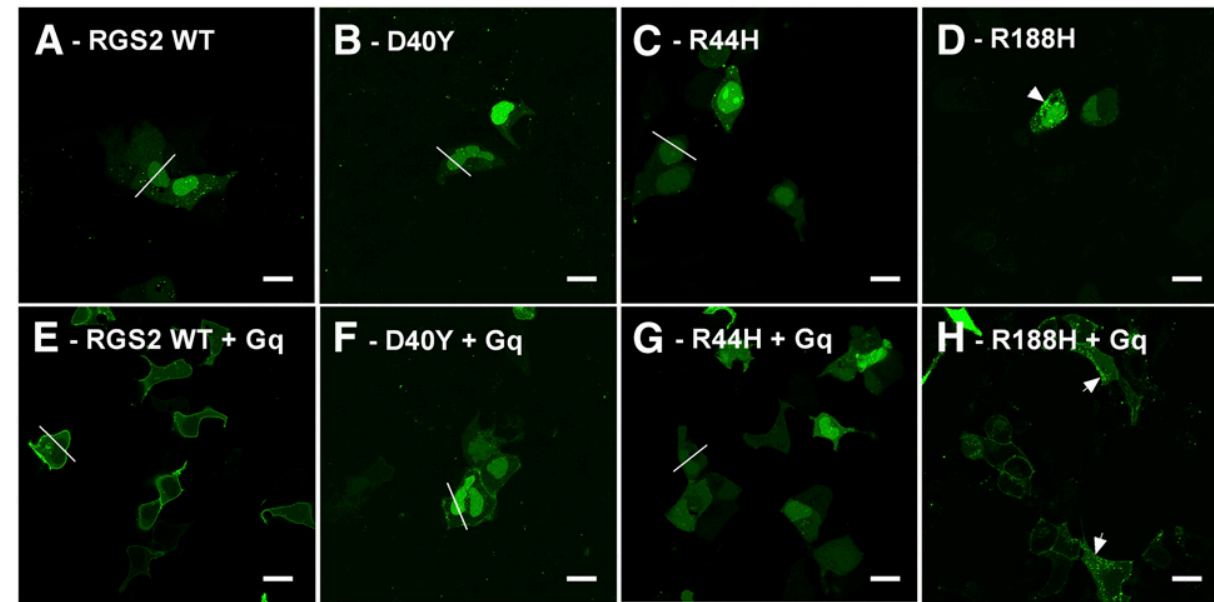

I

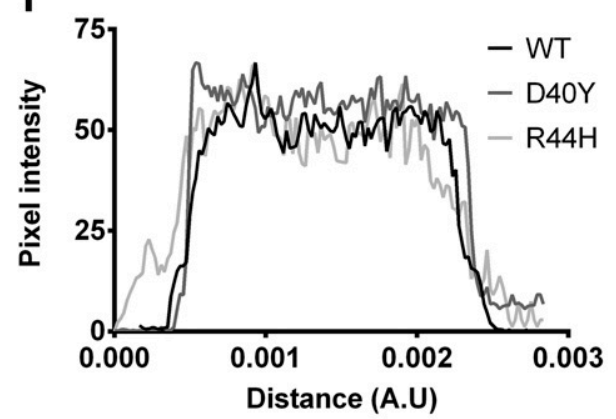

$\mathbf{J}$
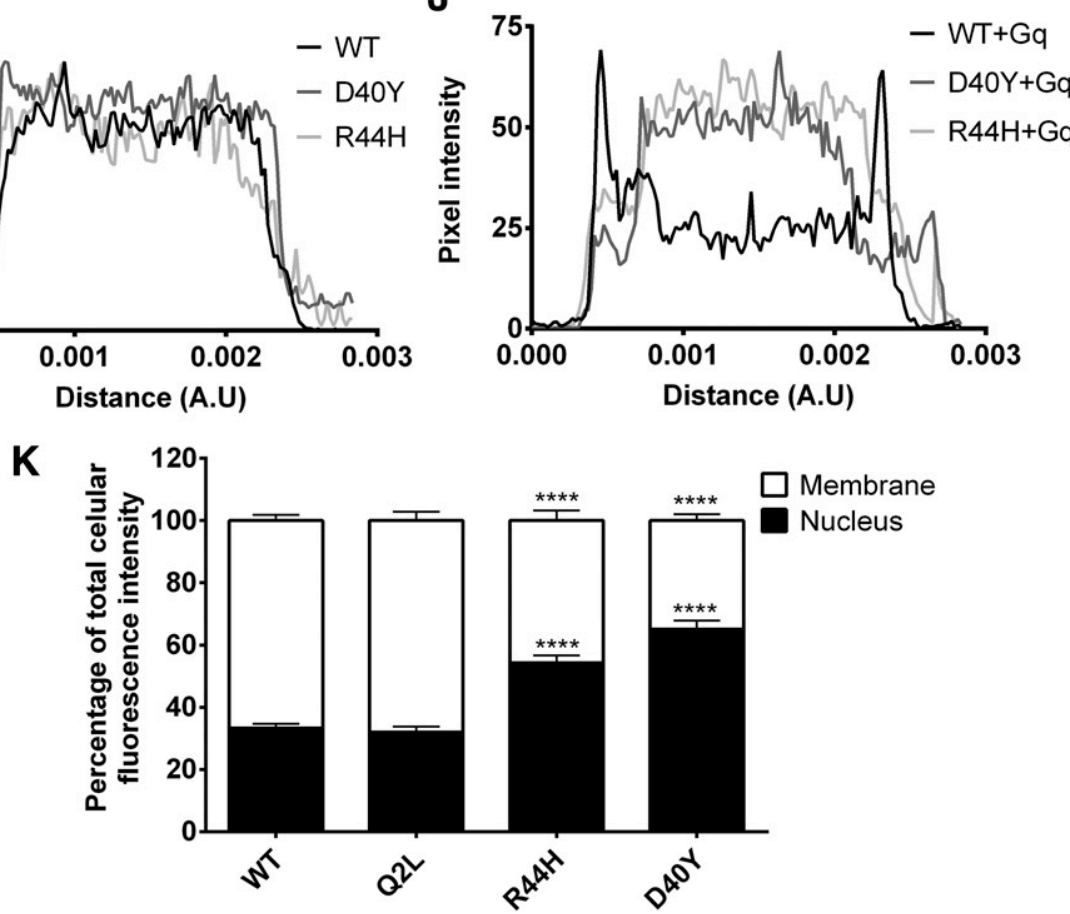

Fig. 3. Effects of RGS2 missense mutations on RGS2-GFP localization. (A-C) When overexpressed in HEK293 cells, RGS2-GFP is localized to the nucleus. (D and $\mathrm{H}$ ) Unlike the other mutants, the R188H-GFP mutant showed punctate intracellular localization. (E) Coexpression of WT-RGS2-GFP with constitutively active $\mathrm{G} \alpha \mathrm{q}$ results in translocation of the RGS2-GFP to the plasma membrane. ( $F$ and $\mathrm{G}$ ) This translocation is impaired with D40Y and R44H; these two mutants remained in the nucleus when coexpressed with $\mathrm{G} \alpha_{\mathrm{q}}$ Q209L. (I) Representative line scans across cells expressing WT, D40Y, $\mathrm{R} 44 \mathrm{H}$ RGS2-GFP without $\mathrm{G} \alpha_{\mathrm{q}}$. (J) Representative line scans across cells expressing $\mathrm{WT}+\mathrm{G} \alpha_{\mathrm{q}}, \mathrm{D} 40 \mathrm{Y}+\mathrm{G} \alpha_{\mathrm{q}}$ or $\mathrm{R} 44 \mathrm{H}+\mathrm{G} \alpha_{\mathrm{q}} .(\mathrm{K})$ Localization of RGS2 in at least 100 cells determined by a blinded observer shows impaired membrane localization of D40Y and $\mathrm{R} 44 \mathrm{H}$. $* * * * P<0.0001$, one-way analysis of variance with Bonferroni post-test (scale bar: $20 \mu \mathrm{m})$. regulator of AT1R due to interaction through its amino terminal domains (Heximer et al., 2003; Hercule et al., 2007; Matsuzaki et al., 2011). As 12 of the RGS2 mutations included in the study are located in the RGS2 amino terminal region (Fig. 1A), a functional screen against AT1R could reveal mutations that selectively disrupt RGS2 protein activity by blocking RGS2-receptor coupling. However, we did not find such mutants in our screen (Fig. $1 \mathrm{~F}$ ). We also did not identify any gain-of-function mutations, despite using conditions that would enable such identification (Supplemental Fig. 2).

Low expression of RGS2 protein resulting in prolonged GPCR signaling has been proposed for hypertension in the case of the rare $\mathrm{Q} 2 \mathrm{~L}$ missense mutation and the common C1114G polymorphism in the 3 '-untranslated region (UTR) of the RGS2 gene (Semplicini et al., 2006; Park et al., 2015). We further confirmed that the Q2L mutant RGS2 has low protein expression (Fig. 2) due to a rapid turnover rate (Supplemental Fig. 4, A and C). No other RGS2 mutants that we investigated had low cellular protein levels in our system (Fig. 2).
The amphipathic $\alpha$ helix at the amino terminus of RGS2 promotes plasma membrane association and affects protein function (Gu et al., 2007). The R44H mutation has been shown to impair RGS2 membrane targeting by interference with lipid bilayer association ( $\mathrm{Gu}$ et al., 2008). In this study, we confirmed that effect of the R44H mutation (Fig. 3, C, G, J, and K). We also identified another mutation in this $\alpha$ helix, D40Y, that exhibited reduced plasma membrane localization (Fig. 3, B, F, $\mathrm{J}$, and K) and function (Fig. 1, C, E, and F). Unlike the R44H mutant in which both residues have a positive charge, the amino acid substitution in D40Y changes from the negatively charged aspartic acid to the hydrophobic tyrosine residue. This more dramatic alteration could explain the somewhat larger effect on $\mathrm{G} \alpha_{\mathrm{q}}$-dependent membrane localization $(\mathrm{R} 44 \mathrm{H}$ : $46 \%$ of control versus D40Y: 35\%; Fig. $3 \mathrm{~K}$ ).

Although protein expression levels and membrane localization indirectly affect the negative regulatory effects of RGS2 on $\mathrm{G} \alpha$-coupled receptor signaling, the interaction between RGS2 and $\mathrm{G} \alpha_{\mathrm{q}}$ protein is absolutely critical for RGS2 function. 
A

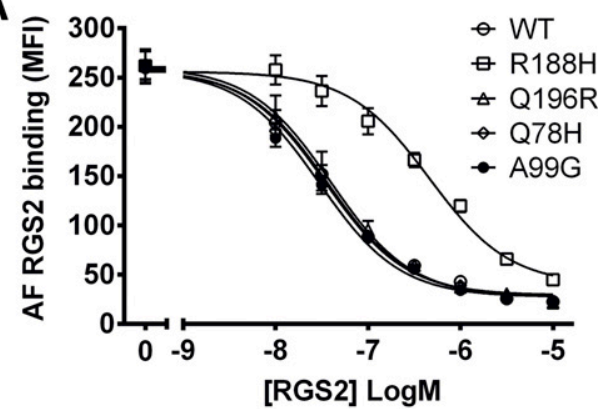

C

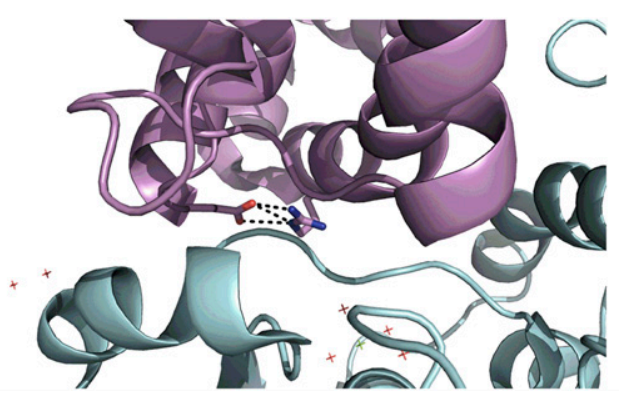

B

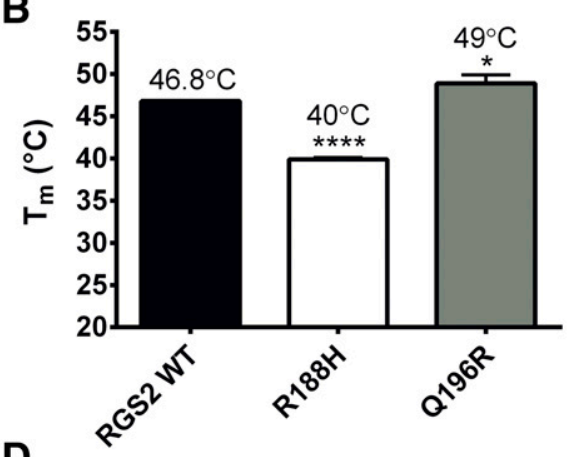

D

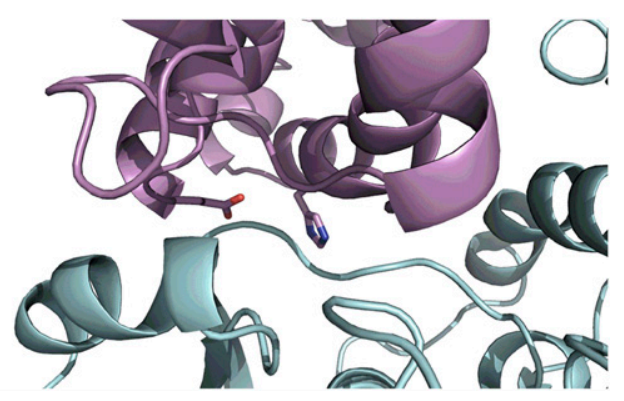

Fig. 4. Impaired $\mathrm{G} \alpha_{\mathrm{q}}$ binding by the R188H mutant. (A) Binding affinities of RGS2 proteins with $\mathrm{G} \alpha_{\mathrm{q}}$ measured in a bead-based flow cytometry competition binding assay. As described in methods, $\mathrm{G} \alpha_{\mathrm{q}}$ was immobilized on beads, and mutant proteins were used to compete for binding of AF532 labeled WT-RGS2. The $\mathrm{R} 188 \mathrm{H}$ mutant exhibited a reduction in $\mathrm{G} \alpha_{\mathrm{q}}$ binding affinity compared with RGS2 WT protein, demonstrated by the rightward shift in the competition binding curve. The Q78H, A99G, and Q196R had comparable binding affinities. (B) Thermoshift analysis of the RGS spanning domains from RGS2 WT, R188H, and Q196R. The bar graph shows the melting temperature of these proteins as mean \pm S.E.M. from three independent experiments. $* P<0.05$; $* * * * P<0.0001$ (one-way analysis of variance with Bonferroni post-test). (C and D) Proposed structural mechanism of the impaired $\mathrm{G} \alpha_{\mathrm{q}}$ binding and thermal instability of the R188H mutant RGS2. Structure of the RGS2 domain (violet) $-\mathrm{G} \alpha_{\mathrm{q}}$ complex (cyan) (Nance et al., 2013) is shown. (C) The WT arginine at position 188 forms salt bridges with the glutamate residue at position 104. (D) Histidine substitution at position 188 does not favor salt bridge formation.
The published crystal structure of the RGS2 domain/G $\alpha_{\mathrm{q}}$ protein complex shows that the arginine residue at position 188 is close to the binding interface between two proteins (Nance et al., 2013). It may also form networked salt bridges (Donald et al., 2011) with the glutamate residue at position 104 to stabilize protein tertiary structure (Fig. 4C). When this arginine is mutated to a histidine residue, the histidine rotamer with the least steric hindrance may not be sufficiently close to E104 to form a salt bridge, potentially rendering RGS2 more flexible and less structurally stable (Fig. 4D).

Besides the lower melting temperature (Fig. 4B), the initial fluorescence of the $\mathrm{R} 188 \mathrm{H}$ mutant with the thermostability dye was noticeably higher than that of the WT and Q196R proteins (Supplemental Fig. 5). This suggests a disruption of basal protein folding. This misfolding could also explain the aggregation of the R188H-GFP in cells in the localization study. Disruption of the binding interface and structural instability properties of the $\mathrm{R} 188 \mathrm{H}$ may explain the reduced binding affinity to $\mathrm{G} \alpha_{\mathrm{q}}$. Further investigation demonstrated that this mutant has a slightly shorter half-life than WT RGS2 (16 \pm 1.5 minutes versus $22 \pm 1.3$ minutes, not statistically significant; Supplemental Fig. 3, B and D) and is also subjected to proteasomal degradation (Supplemental Fig. 6).

The regulatory function of RGS2 in cardiovascular homeostasis is not limited to its inhibitory effect toward $\mathrm{G} \alpha_{\mathrm{q}}$ signaling. RGS2 can also control protein synthesis through interaction with the eukaryotic initiation factor eIF2B, which has been implicated in protection against cardiac hypertrophy (Nguyen et al., 2009; Chidiac et al., 2014). RGS2 may also interact with $\mathrm{G} \alpha_{\mathrm{s}}$ and several adenylate cyclase subtypes to decrease cAMP production in cell-based assays (Salim et al., 2003; Roy et al., 2006). Overall, our study mainly focused on the canonical RGS2 effect to reduce $\mathrm{G} \alpha_{\mathrm{q}}$ signaling. How RGS2 mutants function with respect to these other mechanisms has not been tested, so the 12 mutants with "normal" function here may be perturbed in other ways.
Some common polymorphisms in regulatory regions of RGS2 gene such as in-del mutations in the 3 '-UTR have been shown to contribute to cardiovascular diseases such as hypertension and responsiveness to antihypertensive treatment (Riddle et al., 2006; Semplicini et al., 2006; Zhang et al., 2013; Kvehaugen et al., 2014; He et al., 2015). In this study, we demonstrate that rare mutations in the protein coding region of RGS2 can affect protein function at least in three different ways (protein stability, localization, and G protein binding) and result in signaling deregulation. How the function of RGS2 mutants in vitro correlates with their activities in vascular tissue or in human physiology will need to be determined. The results from this study could guide the development RGS2 transgenic animal models to derive further knowledge about the activity of rare RGS2 mutations in vivo. It will also provide a strategy to selectively target these mechanisms with directed repurposed or novel cardiovascular therapeutics.

\section{Acknowledgments}

The authors thank the Exome Aggregation Consortium and the groups that provided exome variant data for comparison. A full list of contributing groups can be found at http://exac.broadinstitute.org/ about. We also thank Dr. John Tesmer (University of Michigan) for kindly providing MBP-RGS2 plasmid and biotinylated $\mathrm{G} \alpha_{\mathrm{q}}$ protein, Dr. Thomas Dexheimer and Dr. Matthew Bernard (Michigan State University) for their technical assistance in using the Hamamatsu plate reader and the Luminex flow cytometry system, and Vincent Shaw who assisted with protein purification and structural modeling.

\section{Authorship Contributions}

Participated in research design: Phan, Sjögren, Neubig.

Conducted experiments: Phan.

Performed data analysis: Phan, Sjögren, Neubig.

Wrote or contributed to the writing of the manuscript: Phan, Sjögren, Neubig.

\section{References}

Ackerman MJ (2015) Genetic purgatory and the cardiac channelopathies: exposing the variants of uncertain/unknown significance issue. Heart Rhythm 12:2325-2331. 
Adeyemo A, Gerry N, Chen G, Herbert A, Doumatey A, Huang H, Zhou J, Lashley K, Chen Y, Christman M, et al. (2009) A genome-wide association study of hypertension and blood pressure in African Americans. PLoS Genet 5:e1000564.

Bodenstein J, Sunahara RK, and Neubig RR (2007) N-terminal residues control proteasomal degradation of RGS2, RGS4, and RGS5 in human embryonic kidney 293 cells. Mol Pharmacol 71:1040-1050.

Brinks HL and Eckhart AD (2010) Regulation of GPCR signaling in hypertension Biochim Biophys Acta 1802:1268-1275.

Cameron AC, Lang NN, and Touyz RM (2016) Drug treatment of hypertension: focus on vascular health. Drugs 76:1529-1550.

Chidiac P, Sobiesiak AJ, Lee KN, Gros R, and Nguyen CH (2014) The eIF2Binteracting domain of RGS2 protects against GPCR agonist-induced hypertrophy in neonatal rat cardiomyocytes. Cell Signal 26:1226-1234.

de Kloet AD, Liu M, Rodríguez V, Krause EG, and Sumners C (2015) Role of neurons and glia in the CNS actions of the renin-angiotensin system in cardiovascular control. Am J Physiol Regul Integr Comp Physiol 309:R444-R458.

Dominiczak AF and Munroe PB (2010) Genome-wide association studies will unlock the genetic basis of hypertension: pro side of the argument. Hypertension $\mathbf{5 6}$ 1017-1020, discussion 1025.

Donald JE, Kulp DW, and DeGrado WF (2011) Salt bridges: geometrically specific, designable interactions. Proteins 79:898-915.

Franceschini N, Chasman DI, Cooper-DeHoff RM, and Arnett DK (2014) Genetics, ancestry, and hypertension: implications for targeted antihypertensive therapies. Curr Hypertens Rep 16:461.

Freson K, Stolarz K, Aerts R, Brand E, Brand-Herrmann SM, Kawecka-Jaszcz K, Kuznetsova T, Tikhonoff V, Thijs L, Vermylen J, et al.; European Project on Genes in Hypertension Investigators (2007) $-391 \mathrm{C}$ to $\mathrm{G}$ substitution in the regulator of G-protein signalling-2 promoter increases susceptibility to the metabolic syndrome in white European men: consistency between molecular and epidemiological studies. $J$ Hypertens 25(1):117-125.

Fu W, O'Connor TD, Jun G, Kang HM, Abecasis G, Leal SM, Gabriel S, Rieder MJ, Altshuler D, Shendure J, et al.; NHLBI Exome Sequencing Project (2013) Analysis of 6,515 exomes reveals the recent origin of most human protein-coding variants. Nature 493:216-220.

Gibson G (2012) Rare and common variants: twenty arguments. Nat Rev Genet 13 135-145.

Gómez J, Reguero JR, and Coto E (2016) The ups and downs of genetic diagnosis of hypertrophic cardiomyopathy. Rev Esp Cardiol (Engl Ed) 69:61-68.

Gross V, Tank J, Obst M, Plehm R, Blumer KJ, Diedrich A, Jordan J, and Luft FC (2005) Autonomic nervous system and blood pressure regulation in RGS2-deficient mice. Am J Physiol Regul Integr Comp Physiol 288:R1134-R1142.

Gu S, He J, Ho WT, Ramineni S, Thal DM, Natesh R, Tesmer JJ, Hepler JR, and Heximer SP (2007) Unique hydrophobic extension of the RGS2 amphipathic helix domain imparts increased plasma membrane binding and function relative to other RGS R4/B subfamily members. J Biol Chem 282:33064-33075.

Gu S, Tirgari S, and Heximer SP (2008) The RGS2 gene product from a candidate hypertension allele shows decreased plasma membrane association and inhibition of Gq. Mol Pharmacol 73:1037-1043.

Gurley SB, Griffiths RC, Mendelsohn ME, Karas RH, and Coffman TM (2010) Renal actions of RGS2 control blood pressure. J Am Soc Nephrol 21:1847-1851.

He F, Luo J, Zhang Z, Luo Z, Fan L, He Y, Wen J, Zhu D, Gao J, Wang Y, et al. (2015) The RGS2 (-391, C>G) genetic variation correlates to antihypertensive drug responses in Chinese patients with essential hypertension. PLoS One 10:e0121483.

Hercule HC, Tank J, Plehm R, Wellner M, da Costa Goncalves AC, Gollasch M, Diedrich A, Jordan J, Luft FC, and Gross V (2007) Regulator of G protein signalling 2 ameliorates angiotensin II-induced hypertension in mice. Exp Physiol 92: $1014-1022$

Heron M (2016) Deaths: leading causes for 2014. Natl Vital Stat Rep 65:1-96.

Heximer SP, Knutsen RH, Sun X, Kaltenbronn KM, Rhee MH, Peng N, Oliveira-dosSantos A, Penninger JM, Muslin AJ, Steinberg TH, et al. (2003) Hypertension and prolonged vasoconstrictor signaling in RGS2-deficient mice. $J$ Clin Invest 111: $445-452$.

Heximer SP, Watson N, Linder ME, Blumer KJ, and Hepler JR (1997) RGS2/G0S8 is a selective inhibitor of Gqalpha function. Proc Natl Acad Sci USA 94:14389-14393.

Huan T, Meng Q, Saleh MA, Norlander AE, Joehanes R, Zhu J, Chen BH, Zhang B, Johnson AD, Ying S, et al.; International Consortium for Blood Pressure GWAS (ICBP) (2015) Integrative network analysis reveals molecular mechanisms of blood pressure regulation. Mol Syst Biol 11:799.

Kvehaugen AS, Melien Ø, Holmen OL, Laivuori H, Dechend R, and Staff AC (2014) Hypertension after preeclampsia and relation to the $\mathrm{C} 1114 \mathrm{G}$ polymorphism (rs4606) in RGS2: data from the Norwegian HUNT2 study. BMC Med Genet 15:28.

Lek M, Karczewski KJ, Minikel EV, Samocha KE, Banks E, Fennell T, O’DonnellLuria AH, Ware JS, Hill AJ, Cummings BB, et al.; Exome Aggregation Consortium (2016) Analysis of protein-coding genetic variation in 60,706 humans. Nature $\mathbf{5 3 6}$ $285-291$

Levy D, Ehret GB, Rice K, Verwoert GC, Launer LJ, Dehghan A, Glazer NL, Morrison AC, Johnson AD, Aspelund T, et al. (2009) Genome-wide association study of blood pressure and hypertension. Nat Genet 41:677-687.
Li XC and Zhuo JL (2016) Recent updates on the proximal tubule renin-angiotensin system in angiotensin II-dependent hypertension. Curr Hypertens Rep 18:63.

Lind JM and Chiu CL (2013) Genetic discoveries in hypertension: steps on the road to therapeutic translation. Heart 99:1645-1651.

Matsuzaki N, Nishiyama M, Song D, Moroi K, and Kimura S (2011) Potent and selective inhibition of angiotensin AT1 receptor signaling by RGS2: roles of its N-terminal domain. Cell Signal 23:1041-1049.

Mozaffarian D, Benjamin EJ, Go AS, Arnett DK, Blaha MJ, Cushman M, Das SR, de Ferranti S, Després JP, Fullerton HJ, et al.; Writing Group Members, American Heart Association Statistics Committee, Stroke Statistics Subcommittee (2016) Heart disease and stroke statistics-2016 update: a report from the American Heart Association. Circulation 133:e38-e360.

Nance MR, Kreutz B, Tesmer VM, Sterne-Marr R, Kozasa T, and Tesmer JJ (2013) Structural and functional analysis of the regulator of $\mathrm{G}$ protein signaling 2 -g $\alpha \mathrm{q}$ complex. Structure 21:438-448.

Newton-Cheh C, Johnson T, Gateva V, Tobin MD, Bochud M, Coin L, Najjar SS, Zhao JH, Heath SC, Eyheramendy S, et al.; Wellcome Trust Case Control Consortium (2009) Genome-wide association study identifies eight loci associated with blood pressure. Nat Genet 41:666-676.

Nguyen CH, Ming H, Zhao P, Hugendubler L, Gros R, Kimball SR, and Chidiac P (2009) Translational control by RGS2. J Cell Biol 186:755-765.

Osei-Owusu P, Owens EA, Jie L, Reis JS, Forrester SJ, Kawai T, Eguchi S, Singh H, and Blumer KJ (2015) Regulation of renal hemodynamics and function by RGS2. PLoS One 10:e132594.

Osei-Owusu P, Sun X, Drenan RM, Steinberg TH, and Blumer KJ (2007) Regulation of RGS2 and second messenger signaling in vascular smooth muscle cells by cGMPdependent protein kinase. J Biol Chem 282:31656-31665.

Pan S, Naruse H, and Nakayama T (2015) Progress and issues of the genome-wide association study for hypertension. Curr Med Chem 22:1016-1029.

Park SE, Kim JM, Seok OH, Cho H, Wadas B, Kim SY, Varshavsky A, and Hwang CS (2015) Control of mammalian $\mathrm{G}$ protein signaling by N-terminal acetylation and the N-end rule pathway. Science 347:1249-1252.

Rabbani B, Tekin M, and Mahdieh N (2014) The promise of whole-exome sequencing in medical genetics. $J$ Hum Genet 59:5-15.

Riddle EL, Rana BK, Murthy KK, Rao F, Eskin E, O'Connor DT, and Insel PA (2006) Polymorphisms and haplotypes of the regulator of G protein signaling-2 gene in normotensives and hypertensives. Hypertension 47:415-420.

Roman DL, Talbot JN, Roof RA, Sunahara RK, Traynor JR, and Neubig RR (2007) Identification of small-molecule inhibitors of RGS4 using a high-throughput flow cytometry protein interaction assay. Mol Pharmacol 71:169-175.

Roy AA, Baragli A, Bernstein LS, Hepler JR, Hébert TE, and Chidiac P (2006) RGS2 interacts with Gs and adenylyl cyclase in living cells. Cell Signal 18:336-348.

Salim S, Sinnarajah S, Kehrl JH, and Dessauer CW (2003) Identification of RGS2 and type V adenylyl cyclase interaction sites. J Biol Chem 278:15842-15849.

Schork NJ, Murray SS, Frazer KA, and Topol EJ (2009) Common vs. rare allele hypotheses for complex diseases. Curr Opin Genet Dev 19:212-219.

Schulz WL, Tormey CA, and Torres R (2015) Computational approach to annotating variants of unknown significance in clinical next generation sequencing. Lab Med 46:285-289.

Semplicini A, Lenzini L, Sartori M, Papparella I, Calò LA, Pagnin E, Strapazzon G, Benna C, Costa R, Avogaro A, et al. (2006) Reduced expression of regulator of G-protein signaling 2 (RGS2) in hypertensive patients increases calcium mobilization and ERK1/2 phosphorylation induced by angiotensin II. J Hypertens 24:1115-1124.

Shankaranarayanan A, Thal DM, Tesmer VM, Roman DL, Neubig RR, Kozasa T, and Tesmer JJ (2008) Assembly of high order G alpha q-effector complexes with RGS proteins. J Biol Chem 283:34923-34934.

Sun X, Kaltenbronn KM, Steinberg TH, and Blumer KJ (2005) RGS2 is a mediator of nitric oxide action on blood pressure and vasoconstrictor signaling. Mol Pharmacol 67:631-639.

Tang KM, Wang GR, Lu P, Karas RH, Aronovitz M, Heximer SP, Kaltenbronn KM, Blumer KJ, Siderovski DP, Zhu Y, et al. (2003) Regulator of G-protein signaling-2 mediates vascular smooth muscle relaxation and blood pressure. Nat Med 9:1506-1512

Yang J, Kamide K, Kokubo Y, Takiuchi S, Tanaka C, Banno M, Miwa Y, Yoshii M, Horio T, Okayama A, et al. (2005) Genetic variations of regulator of G-protein signaling 2 in hypertensive patients and in the general population. $J$ Hypertens 23 : $1497-1505$.

Zhang C, Wang L, Liao Q, Zhang L, Xu L, Chen C, Ye H, Xu X, Ye M, and Duan S (2013) Genetic associations with hypertension: meta-analyses of six candidate genetic variants. Genet Test Mol Biomarkers 17:736-742.

Zhang W, Anger T, Su J, Hao J, Xu X, Zhu M, Gach A, Cui L, Liao R, and Mende U (2006) Selective loss of fine tuning of Gq/11 signaling by RGS2 protein exacerbates cardiomyocyte hypertrophy. J Biol Chem 281:5811-5820.

Address correspondence to: Dr. Richard R. Neubig, Department of Pharmacology and Toxicology, Michigan State University, B423 Life Sciences building, 1355 Bogue St., East Lansing, MI 48824. E-mail: rneubig@msu.edu 